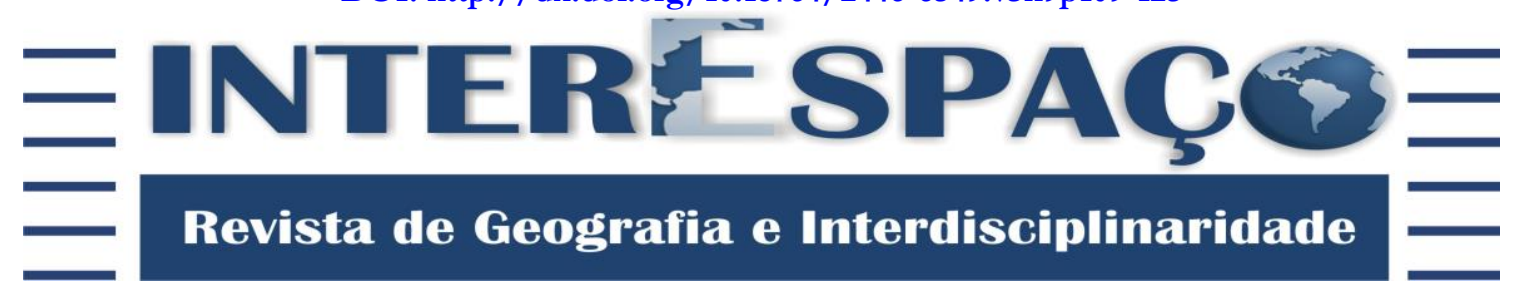

\title{
DESMATAMENTO, BEM-ESTAR COMUNITÁRIO E DESENVOLVIMENTO SUSTENTÁVEL: uma análise integrada em São Tomé e Príncipe - África
}

\author{
DEFORESTATION, COMMUNITY WELLNESS AND SUSTAINABLE \\ DEVELOPMENT: an integrated analysis in Sao Tome and Principe - Africa
}

\author{
DÉFORESTATION, BIEN-ÊTRE COMMUNAUTAIRE ET \\ DÉVELOPPEMENT DURABLE: une analyse intégrée à Sao Tomé-et-Principe - \\ Afrique
}

\author{
Manuel D'Assunção do Nascimento José da Costa \\ Bacharel em Direito pela Universidade Federal do Ceará - UFC. \\ costa_manuel1@hotmail.com
}

\section{Lúcio Correia Miranda}

Doutor em Geografia pela Universidade Federal do Ceará - UFC. Professor da Faculdade de Tecnologia em Geoprocessamento da Universidade Federal do Pará - UFPA/Campus Ananindeua. lcmiranda-ufc@hotmail.com

Recebido para avaliação em 19/09/2016; Aceito para publicação em 01/09/2017.

\begin{abstract}
RESUMO
A preocupação com a natureza, frente aos impactos negativos provocados pela ação humana, tem sido objeto de grande reflexão internacional. Vários eventos já foram realizados sobre a matéria, mormente apelando à conservação dos recursos naturais e à necessidade do desenvolvimento sustentável. Entretanto, atrocidades contra a natureza têm defasado fauna e flora em diversos lugares, como é caso de São Tomé e Príncipe. Eis o objeto do presente trabalho: analisa-se a relação socioambiental no país, sobretudo as causas e efeitos da acentuada prática do desmatamento. E para tanto, usou-se uma metodologia centralizada na revisão da literatura complementada com uma análise interpretativa e reflexiva sobre os problemas ambientais. Assim, convém destacar subsídios teóricos usados: Eiffert (2010); Castro et al. (2005); Filho (2000); Rodriguez et al. ( 2009); Souza et al. (2012). Outrossim, diplomas legais que dispõem sobre a matéria foram de capital importância, sobretudo a Constituição da República Democrática de São Tomé e Príncipe 2003 e da Lei n. ${ }^{\circ}$ 05/2001, Lei de Florestas. No decorrer da análise, constatou-se que o fator desmatamento registrado, em parte, está condicionado ao fator econômico (pobreza), e isso impôs à necessidade da reflexão socioeconômica em conjugação com o fator socioambiental. Por fim, instiga-se a importância de planos estratégicos para uso sustentável de recursos naturais, visando à estabilidade ecológica local. São essas reflexões que deram sustentação e especificidade no desenrolar do presente estudo, o qual se espera ensejar mais reflexões e debates sobre a matéria em epígrafe.
\end{abstract}

Palavras-chave: Impacto Ambiental; Bem-estar Comunitário; São Tomé e Príncipe.

\section{ABSTRACT}

The concern with nature, in the face of the negative impacts caused by human action, has been the object of great international reflection. Several events have already been held on the subject, especially appealing to the conservation of natural resources and the need for sustainable development. However, atrocities against nature have lagged fauna and flora in several places, as is the case of São Tomé and Príncipe. The objective of the present study is to analyze the socio- 
| Manuel D'Assunção do Nascimento José da Costa | Lúcio Correia Miranda |

environmental relationship in the country, especially the causes and effects of the marked deforestation practice. For this purpose, a centralized methodology was used in the review of the literature and complemented with an interpretative and reflexive analysis on the environmental problems. Thus, it is worth mentioning the theoretical subsidies used: Eiffert (2010); Castro et al. (2005); Filho (2000); Rodriguez et al. (2009); Souza et al. (2012). In addition, the legal provisions on this matter were of paramount importance, especially the Constitution of the Democratic Republic of São Tomé and Príncipe 2003 and Law no. 05/2001, Law on Forests. In the course of the analysis, it was found that the recorded deforestation factor, in part, is conditioned to the economic factor (poverty), and this imposed the need for socioeconomic reflection in conjunction with the socio-environmental factor. Finally, the importance of strategic plans for the sustainable use of natural resources is instigated, aiming at the local ecological stability. It is these reflections that gave support and specificity in the course of the present study, which is expected to lead to more reflections and debates on the subject in question.

Keywords: Environmental Impact; Community Well-being; Sao Tome and Principe.

\section{RÉSUMÉ}

La préoccupation de la nature, face aux impacts négatifs causés par l'action humaine, a fait l'objet d'une grande réflexion internationale. Plusieurs événements ont déjà eu lieu sur le sujet, en particulier pour la conservation des ressources naturelles et la nécessité d'un développement durable. Cependant, les atrocités contre la nature ont retardé la faune et la flore dans plusieurs endroits, comme c'est le cas à São Tomé et Príncipe. L'objectif de la présente étude est d'analyser les relations socio-environnementales dans le pays, en particulier les causes et les effets de la pratique de la déforestation. À cette fin, une méthodologie centralisée a été utilisée dans l'examen de la littérature et complétée par une analyse interprétative et réflexive des problèmes environnementaux. Ainsi, il convient de mentionner les subventions théoriques utilisées: Eiffert (2010); Castro et al. (2005); Filho (2000); Rodriguez et al. (2009); Souza et al. (2012). En outre, les dispositions légales sur cette question revêtaient une importance primordiale, en particulier la Constitution de la République démocratique de São Tomé et Príncipe de 2003 et la Loi n ${ }^{\circ}$ 05/2001, Loi sur les forêts. Au cours de l'analyse, on a constaté que le facteur de déforestation enregistré, en partie, est conditionné au facteur économique (pauvreté), ce qui a imposé la nécessité d'une réflexion socio-économique en conjonction avec le facteur socio-environnemental. Enfin, l'importance des plans stratégiques pour l'utilisation durable des ressources naturelles est instigée, en vue de la stabilité écologique locale. Ce sont ces réflexions qui ont apporté un soutien et une spécificité au cours de la présente étude, ce qui devrait conduire à plus de réflexions et de débats sur le sujet en question.

Mots-clés: Impact Environnemental; Bien-être Communautaire ; Sao Tomé-et-Principe.

\section{INTRODUÇÃO}

Antes de proceder a uma análise do meio ambiente em São Tomé e Príncipe, é imperioso tecer alguns comentários sobre a sua história. As ilhas de São Tomé e Príncipe foram descobertas entre 1470 - 71, pelos navegadores portugueses, João de Santarém, Pêro Escobar, e a partir daí o país ficou sob a administração portuguesa até 12 de julho de 1975 , data em que foi proclamada a sua independência. O país localiza-se no Golfo da Guiné, separado pelo Oceano Atlântico a $250 \mathrm{~km}$ da costa ocidental africana. A sua superfície total é de $1001 \mathrm{~km}^{2}$ de área, distribuídas das seguintes formas, ilha de São Tomé, $859 \mathrm{~km}^{2}$ e a ilha de Príncipe $142 \mathrm{~km}^{2}$. A distância entre elas é de $145 \mathrm{~km}$, tendo aproximadamente 200 
| Desmatamento, bem-estar comunitário e desenvolvimento sustentável: uma análise integrada em São Tomé e Príncipe - África|

| Manuel D'Assunção do Nascimento José da Costa | Lúcio Correia Miranda|

mil habitantes em todo território nacional. País possui característica de subdesenvolvimento, sua população predominantemente jovens, economia fragilizada, sobretudo a estrutura económica esteve sempre acometida por forte dependência do exterior e da produção de um único produto de exportação de maior expressão, o cacau. Não obstante, registram-se também outras culturas, como a cana-de-açúcar, café. Atualmente a perspectiva de extração do petróleo pode dar um novo alento à economia.

Os essenciais nortes que orientam a política de desenvolvimento económico-social assentam sobre os seguintes aspectos: crescimento económico; redução da pobreza; reorganização do Estado; promoção da boa governação; reforço da democracia; desenvolvimento humano e a solidariedade. A língua portuguesa é idioma oficial. O país, pois, é o membro da comunidade dos Países Africanos de Língua Oficial Portuguesa Palop, igualmente, o membro da Comunidade dos Países de Língua Portuguesa - CPLP. Entretanto, além da língua portuguesa, registram-se outros idiomas locais (crioulo), tais como: forro e angolar, em São Tomé; e os minu ié, na Ilha Príncipe; há também crioulos dos cabo-verdianos e dos Moçambicanos (tongas), existentes em ambas as ilhas (IV RECENSEAMENTO GERAL DA POPULAÇÃO E HABITAÇÃO, 2012).

Vale lembrar que o propósito da encimada consideração histórica de São Tomé e Príncipe se deve ao fato de ser o país objeto do presente estudo. E empós isso, prosseguese com o exórdio da questão socioambiental ao entorno do mesmo.

A interferência humana na natureza nem sempre acontece ou aconteceu de forma harmoniosa. A ação humana desmedida, originada pelo desejo possessivo de bens materiais, tem destruído imensuravelmente o meio ambiente. No entanto, nem sempre ação humana, devastadora do meio ambiente, está fundada no orgulho possessivo de acumulação desses bens, e sim, numa questão de luta pela sobrevivência. Isto ocorre em alguns lugares do mundo, sobretudo nos países em vias de desenvolvimento, como é o caso de São Tomé e Príncipe. A vulnerabilidade econômica que assola a grande parte da comunidade santomense, mormente nas comunidades das roças ${ }^{1}$, expõe alguns indivíduos às práticas das ações extremamente ofensivas ao meio ambiente. Prova disso é o registro da acentuada prática da produção de carvão vegetal que ocorre no país, a qual, em parte, justifica-se por falta de oportunidade de emprego existente no país. Assim, muitos adultos, jovens e adolescentes recorrem a essa prática para o sustento próprio e da sua família. Porém, a "tal prática tem criado vários constrangimentos ao ambiente local, já bastante

\footnotetext{
${ }^{1}$ Roças: zonas de interior do país, as quais conservam o valor no contexto do patrimônio histórico do país, pois a roças de São Tomé e Príncipe foram de extrema importância para a estrutura económica das ilhas, na era colonial, o pilar da economia do país estava subjacente à cultura de cacau, cana de açúcar, café.
} 
| Desmatamento, bem-estar comunitário e desenvolvimento sustentável: uma análise integrada em São Tomé e Príncipe - África|

| Manuel D'Assunção do Nascimento José da Costa | Lúcio Correia Miranda|

impactado por alterações climáticas que têm sido constatadas nos últimos anos no país” (FERNANDES, 2014).

O abatimento massivo e contínuo das árvores, além da produção do referido carvão, se deve às outras finalidades, tais como: a construção de residência, a fabricação da canoa de pesca, as obras de artesanatos, os móveis de diversos tipos, a lenhas para cozer os alimentos. Em vista disso, faz da madeira a matéria prima de suma importância para os santomenses, principalmente os de baixa renda. E consequentemente a demanda desse material no mercado interno é intensa. Afora o seu comércio internacional, que não será objeto da presente análise.

A Direção da Floresta em São Tomé e Príncipe tem ciência da ocorrência. Inclusive há legislação específica, Lei n. ${ }^{\circ}$ 05/2001, lei da floresta, cujo artigo $36^{\circ}$ determina expressamente a proibição do abatimento das árvores no país. No entanto, parece que a necessidade de sobrevivência faz com que as comunidades não deem os devidos cumprimentos ao comentado instrumento normativos. Isso torna mais evidente com a pronúncia feita, numa revista na televisão santomense - TVS, pelo diretor da floresta, Faustino d'Oliveira, sobre o incalculável abatimento ilegal das árvores que acontece dia a dia no país (OLIVEIRA, 2012). Este, ainda, esclarece que "há uma maior pressão das pessoas a procura de madeira para os diversos fins".

Assim, corte de árvore que ocorre de forma reiterada e contínua tem como efeito o desmatamento, que, por sua vez, pode levar à extinção da biodiversidade existente na região. Desta maneira, sustenta-se a necessidade de plano ecológico com vista ao desenvolvimento sustentável. Não obstante, indaga-se sobre a questão de sobrevivência dessa comunidade, pois as práticas das ações que causam distúrbio a estabilidade ecológica, em alguns casos, impõem-se como a única alternativa de sobrevivência. Lembre-se que a maior parte da população enquadra na categoria dos hipossuficientes, vulnerável economicamente, ou seja, ainda que houvesse outro meio alternativo, os recursos para sua aquisição, por parte dessas pessoas, são insuficientes. E o Estado pouco tem feito nesse sentido. Importa frisar que o Estado além de se preocupar com o equilíbrio ecológico, este, igualmente, tem o dever de se preocupar com o bem estar humanitário, isto é, promover políticas públicas voltadas à educação, à saúde, com vista a atribuir as condições mínimas à comunidade.

Portanto, resta evidenciado que o trabalho visa proceder à análise da relação socioambiental em São Tomé e Príncipe, especificamente abordar sobre as causas e efeitos da acentuada prática do desmatamento local. Por outro lado, foi imprescindível fazer 
| Desmatamento, bem-estar comunitário e desenvolvimento sustentável: uma análise integrada em São Tomé e Príncipe - África|

| Manuel D'Assunção do Nascimento José da Costa | Lúcio Correia Miranda|

abordagem do fator socioeconômico, uma vez que ficou patente que a prática do desmatamento registrado no país, em parte, está condicionada à debilidade econômica que assola a Nação, e isso impôs a necessidade da reflexão socioeconômica em paralelo com a socioambiental. Ou seja, o trabalho, de um lado, debruça sobre a análise das práticas de desflorestamentos e seus reflexos no meio ambiente, a fim de destacar a importância de um plano de manejo alternativo e sustentável dos recursos naturais e; do outro lado, traz articulação de influência do fator econômico que pode estar subjacente à referida prática.

E para tanto, usou-se uma metodologia centralizada na revisão da literatura complementada com uma análise interpretativa e reflexiva sobre os problemas ambientais. Assim, convém destacar subsídios teóricos usados: Eiffert (2010); Castro et al. (2005); Filho (2000); Rodriguez et al. (2009); Souza et al. (2012). Os diplomas legais que dispõem sobre a matéria foram igualmente de capital importância à consumação do presente trabalho, sobretudo a Constituição da República Democrática de São Tomé e Príncipe 2003 e da Lei n. ${ }^{\circ}$ 05/2001, Lei de florestas. Outrossim, vale frisar que auxílio de diversas fontes virtuais que tratam da matéria, os quais podem ser destacados os sites das instituições como: Téla Nón, Deutsche Welle - WD, Terra Gaia, Tiba, foram extremamente gratificante haja vista a carência dos documentos físicos relativamente à matérias em epígrafe.

Pertinente esclarecer que a pretensão do presente estudo não é expor as minúcias relativas ao desflorestamento e nem tão pouco exaurir sobre as condições precárias existentes em algumas comunidades santomenses, mas sim realçar sobre o grau da periculosidade em que o fator desmatamento pode representar ao arquipélago. E assim, instigar a necessidade de medidas, planos estratégicos, que possam contribuir ao progresso ecológico e, ao mesmo tempo, promover o bem estar comunitário.

No que tange à estrutura da organização do trabalho, no primeiro momento fez-se o breve comentário histórico sobre a República Democrática de São Tomé e Príncipe, (RDSTP). Empós, prosseguiu-se com as considerações do meio ambiente e respectivo impacto ambiental provocado exclusivamente pela ação humana (desmatamento), e neste contexto realçou-se a importância do plano sustentável; e em seguida fez-se abordagem socioeconômica. As condições sociais desfavoráveis como pobreza, miséria, que assola a grande parte da comunidade santomense são elementos que dificultam e até mesmo impossibilitam uma determinada comunidade a pensar de modo sustentável o bem estar da Natureza. Entende-se, pois, que a comunidade santomense, muitas vezes, não é vulnerável culturalmente, e sim a circunstância, por razões econômicas, impulsiona às condições de vulnerabilidades materiais. E por último, nas considerações finais, fez-se uma articulação de 
| Desmatamento, bem-estar comunitário e desenvolvimento sustentável: uma análise integrada em São Tomé e Príncipe - África|

| Manuel D'Assunção do Nascimento José da Costa | Lúcio Correia Miranda|

dos vários aspetos que foram abordados no sentido de proceder a uma reflexão lógica da temática em voga. Enfim, espera-se que o presente estudo seja uma das formas da materialização e da contribuição aos estudos socioambiental ao entorno do arquipélago santomense.

\section{CONSIDERAÇÃO TEÓRICA SOBRE O MEIO AMBIENTE}

$\mathrm{Na}$ busca pela satisfação das necessidades e dos desejos sedentos das acumulações dos bens materiais, o homem recorre à exploração dos recursos naturais, muitas vezes, de modo irracional alterando o dinamismo do ecossistema e provocando consequentemente o impacto negativo ao meio ambiente. Este, considerado como "qualquer alteração das propriedades físicas, químicas e biológicas do meio ambiente, causada por qualquer forma de matéria ou energia resultante das atividades humanas" (CONAMA, ${ }^{2}$ 1986, art. 1). Tais impactos afetam, direta ou indiretamente, a saúde, a segurança e o bem-estar da população; as atividades sociais e econômicas; a biota; as condições estéticas e sanitárias do meio ambiente; a qualidade dos recursos ambientais.

Entende-se, pois, que os impactos ambientais são manifestados através das intensas explorações dos recursos naturais, e concomitantemente dos diferentes resíduos industriais provenientes do processo das transformações desses mesmos recursos. A subtração inadequada do componente natural e o acréscimo de novo componente, em forma de resíduo, que, em muitas vezes, são incompatíveis com o sistema ecológico, provocam implicações e alterações no ecossistema, refletindo aspectos extremamente negativos ao meio ambiente (MIRANDA, 2013).

São as mais variadas, as ações, exclusivamente humana, que levam às alterações do sistema ecológico, dentre elas, pode-se acentuar a prática de desmatamento. Entende-se que esta prática é extremamente ofensiva à estabilidade ecológica. Corte das árvores não se limita somente na distribuição das vidas das árvores, e sim abarca um patamar bem mais amplo. Segundo Cavalcanti (2004), o desflorestamento é altamente prejudicial à estabilidade ecológica, pois no processo de eliminação de uma floresta ocorre à destruição das árvores e, simultaneamente, acarreta a morte de muitas outras espécies animais que fazem da floresta o lugar de seu habitat.

2 CONAMA: Conselho Nacional do Meio Ambiente (instituição brasileira), "é o órgão consultivo e deliberativo do Sistema Nacional do Meio Ambiente-SISNAMA, foi instituído pela Lei 6.938/81, que dispõe sobre a Política Nacional do Meio Ambiente, regulamentada pelo Decreto 99.274/90”. 
| Desmatamento, bem-estar comunitário e desenvolvimento sustentável: uma análise integrada em São Tomé e Príncipe - África|

| Manuel D'Assunção do Nascimento José da Costa | Lúcio Correia Miranda|

É necessário, portanto, que a humanidade se conscientize sobre as suas ações no relacionamento com a natureza, principalmente aquelas que refletem maiores graus de ofensividade ao meio ambiente, como é o caso do desmatamento, mormente feito pelo processo de queimada. Assim, é extremamente importante a concretização de práticas alternativas de exploração de recursos naturais através de medidas de planejamento e gestão, sobretudo levando em consideração a especificidade de cada ambiente a ser explorado, a fim de se alcançar o desenvolvimento sustentável. Este, definido na concepção do Seiffert (2010), como o mecanismo que vise utilizar de modo adequado os recursos naturais sem que possa comprometer a necessidade das futuras gerações.

Vale lembrar que na antiga concepção da preservação ambiental, o que prevalecia era a intocabilidade dos recursos naturais. Porém, a tal concepção já foi superada. É necessário, pois, haver a "tocabilidade" desses recursos, mas com fundamento no uso racional, isto é, possibilidade de gerenciamento para conservá-lo, fortalecer a sua fonte, para que estejam disponíveis as gerações futuras. A tocabilidade de recursos naturais tem o propósito de promover o desenvolvimento sustentável e não de esgotar abusivamente esses recursos (FILHO, 2000). Portanto, entende-se que o desenvolvimento sustentável deve trilhar a lógica do equilíbrio entre o crescimento econômico, sustentabilidade ambiental e a equidade social.

O processo de desenvolvimento sustentável consistiria em assumir a sustentabilidade ambiental como o elemento decisivo na gestão, quer dizer, como o manejo do âmbito para o qual as categorias restantes da sustentabilidade (a econômica, a social e a cultural) deveriam adaptar-se (RODRIGUEZ e SILVA, 2009, p. 75).

Não resta dúvida quanto à necessidade do progresso em outros setores sociais, entretanto, o que se quer aqui enfatizar, é que esses progressos devem ocorrer respeitando os princípios que norteiam a estabilidade ambiental, uma vez que o desenvolvimento sustentável deve ocupar o maior destaque no relacionamento entre o homem e o meio ambiente. Enfim, é necessário que haja promoções de mais estudos, debates, eventos sobre a matéria. Ademais Moraes (1995, p. 127) sustenta que “onde há discussão há vida, onde há debate aflora o pensamento crítico, onde há polêmica há espaço para o novo, para a criação". Por isso, acredita-se que a reflexão, o debate, o planejamento são instrumentos necessários, e devem ser levados em considerações, antes mesmo de quaisquer medidas ou práticas que possam acarretar em danos que, muitas das vezes, são irreversíveis. 


\title{
RELAÇÕES SOCIOAMBIENTAIS E DESENVOLVIMENTO COMUNITÁRIO EM SÃO TOMÉ E PRÍNCIPE
}

A conservação da natureza em São Tomé e Príncipe pode ser fator crucial à existência do próprio arquipélago, pois “São Tomé e Príncipe está sempre atento aos movimentos do aquecimento global e da subida do nível do mar. Para o jovem país [...], a preservação do meio ambiente é literalmente uma questão de vida ou morte" (LETRA, 2010).

Aliás, de acordo com o site do Centro de Ciência do Sistema Terrestre (2011), já houve registro do desaparecimento de arquipélago no mundo.

\begin{abstract}
A ameaça não é nova, mas agora veio a confirmação científica [...]. O mundo tal como o conhecemos está mesmo a mudar. Cinco ilhas do arquipélago Salomão já deixaram de fazer parte do mapa, segundo uma investigação australiana publicada na revista científica Environmental Research Letters. E a culpa é do aquecimento global, consequência directa das mudanças climáticas que o mundo enfrenta.
\end{abstract}

Destarte, a interferência do ser humano em relação ao meio ambiente, sobretudo, nos países com caraterísticas de arquipélago (ilhas), deveria ocorrer com maior cautela. Não se pode olvidar da catástrofe vulcânica ocorrida no Cabo Verde, cujos danos materiais foram avaliados em mais de 45 milhões de euros (RELVAS, 2015). O Cabo Verde e São Tomé e Príncipe, ambos fazem parte dos arquipélagos pertencentes ao continente africano.

Decerto, não há que se negar o relevo atinente à conservação ambiental em São Tomé e Príncipe, no entanto, tem registrado no país diversas práticas que acarretam em perturbações ambientais, dentre as quais se pode destacar o desmatamento. Segundo Veiga (2012), a Direcção das Florestas não consegue mensurar o número de árvores que são ilegalmente abatidas em São Tomé e Príncipe. Diante disso, foi promovida a campanha denominada Plantar São Tomé e Príncipe, em que a Direção das Florestas pretende sensibilizar toda a população, sobretudo os mais novos, sobre a importância da cultura das árvores no arquipélago. Faustino d'Oliveira, na qualidade de Diretor das Florestas, numa entrevista ao Téla Nón” ${ }^{3}$ comenta que "o sector já tem 20 mil árvores em viveiros para serem plantadas este ano em mais de 800 hectares de terras identificadas como de risco, devido ao abate abusivo e ilegal de árvores” (Téla Nón, 2012).

É pertinente, mais uma vez, destacar as razões que levam a comunidades ao corte abusiva de árvores, quais sejam: construção de casa, fabricação de mobília, extração de

\footnotetext{
3 Téla Nón é uma das fontes de notícias de São Tomé e Príncipe e pode ser equiparado a um jornal online. Téla Nón, em português, significa Nossa Terra.
} 
| Desmatamento, bem-estar comunitário e desenvolvimento sustentável: uma análise integrada em São Tomé e Príncipe - África|

| Manuel D'Assunção do Nascimento José da Costa | Lúcio Correia Miranda|

carvão, fabricação de canoa de pesca, lenha para confecções dos alimentos, obras de artesanatos. Eis a justificativa da forte comercialização de madeira no interior do país.

O fator socioeconômico, como a pobreza, que assola a grande parte da comunidade santomense, pode condicionar, em alguns casos, ao desmatamento e consequentemente efeitos negativos no processo do desenvolvimento sustentável local. Segundo Fernandes et al. (2014), publicado no Terra Gaia ${ }^{4}$, foi realizada uma pesquisa do campo pelo grupo de jornalistas ambientais, na qual, foram entrevistados vários carvoeiros ${ }^{5}$ no norte da Ilha de São Tomé, concretamente no Distrito de Lobata, onde a prática de extração de carvão ocorre com mais frequência. Dentre adultos, jovens e adolescentes entrevistados, em destaque a observação do Senhor Ermindo da Graça:

Tenho cinco filhos, sou carvoeiro há cerca de 20 anos e não tenho outros meios de subsistência desde que fui licenciado na empresa ECOMI. [...] Aqui consigo produzir diariamente por volta 3 a 4 sacos de carvão, e vendo as palaiês ${ }^{6}$ no valor de 60 a 70 mil dobras (cerca de US\$3) na época de gravana (período de seca). No período das chuvas consigo vender por 80 a 90 mil dobras (cerca de US\$4), o que, na minha opinião, dá pra safar.

O senhor Ermindo da Graça resignadamente, ainda no decorrer da entrevista, manifestou os seguintes: "Sei que esta prática diminui a frequência da chuva, diminui a produção agrícola, e até mesmo prejudica a minha própria saúde, mas não há como sustentar a minha família de outra forma”. Eis a evidência da sustentação aqui colocada, quando se defende que as comunidades santomenses, muitas das vezes, não são vulneráveis intelectualmente, e sim as circunstâncias, por razões econômicas, ou por outras razões alheias as suas vontades, impulsionam às condições de vulnerabilidades materiais e consequentes vulnerabilidades ambientais. Percebe-se que as pessoas embora mostrassem conscientizadas sobre os eventuais efeitos negativos gerados exclusivamente pelas suas ações em desfavor à natureza, eles, de modo resignado, permanecem na atividade, haja vista ser a única fonte de renda para o próprio sustento e da sua família. Isto é, a verdadeira luta pela sobrevivência.

Oportuno deixar evidente que a Constituição (2003), da República Democrática de São Tomé e Príncipe, em diferentes momentos enfatiza sobre a vida. Assim, o artigo 22. ${ }^{\circ}$ determina que "a vida humana é inviolável”; mais adiante no artigo 49. 1 , dispõe que "todos têm direito à habitação e a um ambiente de vida humana e o dever de o defender";

\footnotetext{
4 TerraGaia é um sitio online, mas o termo Gaia está subjacente à Teoria de Gaia, igualmente também conhecida por Hipótese de Gaia, é uma tese que afirma que o planeta Terra é um ser vivo.

${ }^{5}$ Carvoeiros: pessoas que fazem, vendem ou transportam carvão.

${ }^{6}$ Palaiês: vendedoras ambulantes do mercado, semelhante às feirantes na grafia Brasileira.
} 
| Desmatamento, bem-estar comunitário e desenvolvimento sustentável: uma análise integrada em São Tomé e Príncipe - África|

| Manuel D'Assunção do Nascimento José da Costa | Lúcio Correia Miranda|

no mesmo artigo, linha 2, acrescenta que "incumbe ao Estado programar e executar uma política de habitação inserida em planos de ordenamento do território”. Entende-se que o legislador constituinte trouxe o destaque à vida, em diferentes momentos, talvez como a forma de exclamar que a vida é o maior patrimônio do ser humano.

Todavia, tem-se a vida da natureza, necessidade de conservá-la, ademais a natureza é a mãe de todas as vidas. Por isso, entende-se que é necessária haver no caso concreto, a ponderação, a adequação, isto é, o planejamento buscando as mediadas alternativas que levam aos desenvolvimentos sustentáveis. Assim, é de louvar o projeto arquitetônico de baixo impacto ambiental levado a cabo na zona de Lobata, Ilha de São Tomé, o qual consolidou na construção da casa, em base de blocos de adobe, de cascaje e de pau-a-pique. O supracitado projeto, inicialmente, visou em capacitar os pedreiros e marceneiros da região (TIBA, 2012).

Percebe-se que o objetivo central desse projeto é tentar estabelecer harmonia entre o bem estar comunitário (direito à habitação) e o desenvolvimento sustentável (redução de impacto ambiental). No entanto, muito ainda há de ser feito neste sentido, pois segundo o diretor-geral do ambiente, Arlindo Carvalho, 90\% da casa no país é construído a base de madeira (DEUTSCHE WELLE, 2012).

Lembre-se que além de construção, há outros fatores que levam igualmente à corte das árvores no país, e isso tem despertado atenção, sobretudo dos órgãos competentes do governo, sobre a necessidade de promoção de novos planos e estratégias relativamente a este assunto. Assim vale destacar a entrevista conferida pelo Ministro da Agricultura, Senhor Ovídio Pequeno (2010), sobre a matéria junto a Rádio ONU em Nova York:

\footnotetext{
O Ministério da Agricultura e as autoridades competentes têm feito um trabalho para impedir que se continue a abater essas árvores. Isso tem a ver com a procura da lenha, porque nas áreas rurais de São Tomé a lenha é utilizada para se fazer as refeições. Em nível dos serviços competentes, o trabalho tem sido feito no sentido de explicar e educar as pessoas que se continuarmos a ter este tipo de comportamento, estaremos a condenar as gerações futuras em matéria de sobrevivência e da proteção do meio ambiente. [...] a derrubada indiscriminada de árvores está pondo em risco a flora são-tomense como um todo.
}

Destarte, restaram evidenciados os diferentes motivos subjacentes aos abatimentos das madeiras em São Tomé e Príncipe. Motivos esses que, numa prima face, estão fundados na necessidade de sobrevivência dos residentes. Porém há outros motivos que se entende ser paliativos, infundados, estes devem ser obstaculizados em prol da estabilidade ambiental. Como é o caso de desmatamento para aplicação de um novo projeto, com o 
| Desmatamento, bem-estar comunitário e desenvolvimento sustentável: uma análise integrada em São Tomé e Príncipe - África|

| Manuel D'Assunção do Nascimento José da Costa | Lúcio Correia Miranda |

desprezo do plano sustentável, e acima de tudo sem levar em conta a especificidade de cada ambiente, dando, simplesmente, a prioridade aos bens materiais em detrimento do bemestar ecológico. Prova disso, é o acordo assinado em 2009 entre o Governo santomense com a empresa Agripalma ${ }^{7}$, Belga Socfinco S. A.

O acordo em questão concede cinco mil hectares de terra para monocultura de palmeiras $^{8}$, distribuídas na zona sul de São Tomé e no norte da ilha do Príncipe. Foi destruído todo manto verde, juntos as demais biodiversidades existentes no local, com vista à cultura do único plantio da árvore, para produção de andim (equivalente ao dendê no Brasil), e posteriormente transformados em óleo (VEIGA, 2009). Assim entende-se pertinente trazer a demonstração do local a ser destruído.

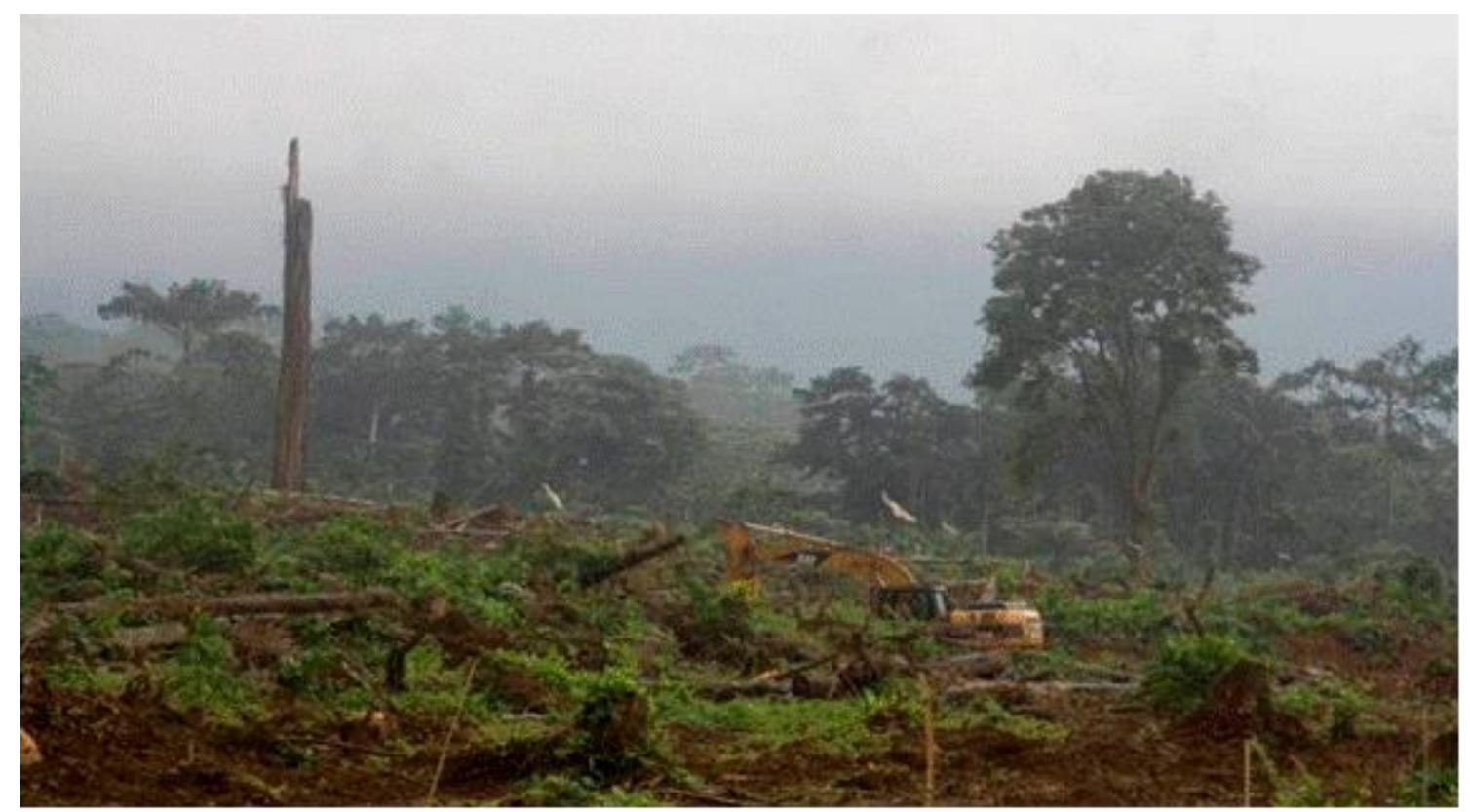

Figura 1 - Desmatamento na zona sul, Ribeira Peixe, Ilha de São Tomé Fonte: Téla Nón, 2013.

No tocante à cultura da palmeira em detrimento das biodiversidades destruídas, oportuno trazer-se reflexão da professora de Física e Química, Pierret (2013, grifo nosso), a respeito:

Realmente, a alta lucratividade do óleo de palma atrai investidores e promove a substituição das florestas tropicais com a monocultura de palma, mas não sem causar problemas ecológicos significantes. A destruição de florestas tropicais e turfeiras acaba contribuindo para o aumento da produção de emissão de gases de efeito estufa e impacta a biodiversidade pois reduz o habitat de várias espécies endêmicas, como os orangutangos.

\footnotetext{
${ }^{7}$ Agripalma: empresa industrial de óleo de palma, equivalente ao azeite de dendê ou azeite de dendém.

${ }^{8}$ Palmeiras: árvores que produz andim, equivalente ao dendezeiro na grafia brasileira.
} 
| Desmatamento, bem-estar comunitário e desenvolvimento sustentável: uma análise integrada em São Tomé e Príncipe - África|

| Manuel D'Assunção do Nascimento José da Costa | Lúcio Correia Miranda|

Inobstante a ilustre reflexão da professora, haja vista o subsídio científico, acreditase que não é necessário grande esforço intelectual para entender-se que esta ação pôs em causa a fauna e a flora existente naquela região. Por outro lado, como não bastasse o arrasamento da biodiversidade ali existente, segundo jornalista, Abel Viegas (2009), a empresa Agripalma, em busca de espaço para monocultura, o trator da referida empresa no processo de desmatamento provoca tanto distúrbio que, inclusive, aproximou-se da área da conservação natural da ilha, o Parque Nacional Ôbo (VEIGA, 2009).

Os Parques Naturais Ôbos ${ }^{9}$, das ilhas de São Tome e de Príncipe, são áreas de conservações naturais, criados em 2006, com finalidade de proteção da biodiversidade existente no país. Os parques são marcados, internacionalmente, pelos ambientalistas, devido as suas florestas densas e ricas em biodiversidades. As referidas florestas já foram consideradas como a segunda mais importante, relativo ao interesse biológico, das 75 florestas dos países africanas (ePORTUGUÊSe, 2013).

Entende-se, embora o projeto traga os recursos financeiros que poderão ser aplicados em alguns setores sociais (educação, saúde, além de ampliar a demanda do poder empregatício), é necessário, também, que se pense no desenvolvimento sustentável. Isso quer dizer que antes adotar medida que acarreta, de forma imensurável, em extinção da biodiversidade existente no país, necessário se faz o estudo prévio e severo sobre o assunto e, assim, apontando as vantagens e as desvantagens da suposta execução do projeto. Com isso, selecionar os melhores ideais à cristalização do plano de manejo alternativo e sustentável.

A título de ilustração, é importante frisar, em 2012, a floresta do país, no ranking internacional, foi considerada como uma das duzentas mais importantes do mundo, em termos de biodiversidade (LOPES, 2012).

É importante, de igual modo, deixar evidente que a sobrecarga da Terra já se tornou realidade, pois, há insuficiência dos recursos naturais no mundo. De acordo com a Rede da Pegada Global (GFN, na sigla em inglês), "organização internacional pela sustentabilidade, parceira global da Rede $\mathrm{WWF}^{10}$, que monitora a Pegada Ecológica das cidades do mundo inteiro", o limite anual de consumo de recurso natural no mundo acaba de ser ultrapassado. Foi definido o dia 8 de agosto de 2016, dia da Sobrecarga da Terra, consequência do uso inadequado e irrefletido dos recursos naturais, pois entre o $1^{\circ}$ de

\footnotetext{
9 Ôbos: são nomes atribuídos às florestas, onde não é registrada alteração, floresta no seu estado puro, floresta prima.

${ }^{10}$ World Wildlife Fund (WWF): é uma ONG, participante de uma rede internacional e comprometida com a conservação da natureza dentro do contexto social e econômico brasileiro. Disponível em: < http://www.wwf.org.br/wwf brasil/organizacao/>. Acesso em: 04 nov. 2015.
} 
| Desmatamento, bem-estar comunitário e desenvolvimento sustentável: uma análise integrada em São Tomé e Príncipe - África|

| Manuel D'Assunção do Nascimento José da Costa | Lúcio Correia Miranda|

outubro em 2000 a 08 de agosto em 2016, em menos de oito meses o mundo esgotou recurso que deveria servir para doze meses, a data tem surgido cada vez mais cedo (WORLD WILDLIFE FUND, 2016).

Ex positis, urge refletir sobre a interação sociedade-natureza, adotando medidas protetivas e conservador, como por exemplo, adoção do Sistema de Gestão Ambiental (SGA). Este, no pensamento do Gilbert (1995 apud Souza et al., 2012, p. 21),

é controlar sistematicamente o desempenho ambiental, promovendo sua melhoria contínua. É constituído de procedimentos ambientais que estabelecem responsabilidades específicas e definem quando, onde e o que deve ser observado, para que as atividades sejam conduzidas em conformidade com as políticas ambientais estabelecidas, e integrado aos esforços existentes em outras áreas.

Entende-se que, para tanto, é de capital importância o envolvimento da comunidade local no plano definido, pois a cooperação dos residentes é extremamente fundamental para o alcance dos propósitos planeados (o desenvolvimento sustentável). Neste contexto é fundamental haver políticas públicas que visem estabelecer as condições mínimas aos residentes, fator socioeconômico. Zatti (2007) realça que as condições sociais desfavoráveis como a pobreza e miséria condicionam a um pensar e a um agir não autênticos e autônomos, o que implica em situações de heteronomia. Outrossim, Freitas (2013, p. 411) salienta que:

Algumas pessoas pobres também teriam a sua liberdade duvidada, uma vez que a sua capacidade de escolha, particularmente, para o trabalho, diante das opções que lhe são disponíveis, são geralmente, muito limitadas, e muitas das que existem, sequer são atraentes".

Assim, entende-se que sejam urgentes e prioritárias as iniciativas públicas que possam combater, positivamente, o cenário social, como a pobreza que assola a grande parte das comunidades santomenses. De outro lado, necessário se faz a promoção da política pública voltada à educação ambiental. Oportuno destacar que o direito à educação, à habitação, à saúde, junto ao direito/dever de conservação do meio ambiente, são igualmente direitos/deveres fundamentais nos termos da Constituição (2003), de São Tomé e Príncipe. O artigo 10. ${ }^{\circ}$, alínea "b" e “d”, do mencionado instrumento normativo, determinam que o Estado tem o dever de "Promover o respeito e a efectivação dos direitos pessoais, económicos, sociais, culturais e políticos dos cidadãos". Outrossim "Preservar o equilíbrio harmonioso da natureza e do ambiente". O preceito constitucional deixa a clara o 
| Desmatamento, bem-estar comunitário e desenvolvimento sustentável: uma análise integrada em São Tomé e Príncipe - África|

| Manuel D'Assunção do Nascimento José da Costa | Lúcio Correia Miranda|

irrefutável dever do Estado em promover políticas públicas visando tanto à proteção do meu ambiente, como a de promover o respeito e efetivação dos demais direitos.

Especificamente, no tocante à corte das árvores, tem-se, no âmbito infraconstitucional, a Lei n. ${ }^{\circ}$ 05/2001, Lei da Floresta, cujo artigo $36^{\circ}$ dispõe que "Fica expressamente proibido o abate de árvores de qualquer espécie com diâmetro à altura do peito abaixo de $70 \mathrm{~cm}$, com casca". No entanto, as práticas reiteradas e contínuas de abatimentos das árvores no país demonstram que a correspondência da expectativa do referido preceito legal está muito aquém de ser alcançada. Entende-se que a não observância da comentada legislação, pelos residentes, em parte, está condicionada ao não respeito e efetivação, pelo Estado, dos direitos contidos na linha "b" do artigo 10., da Constituição da República Democrática de São Tomé e Príncipe 2003.

Pinsky (1998) acentua que "o pressuposto da existência da lei é o de que elas sejam aplicadas". Igualmente o autor manifesta que "às vezes, até, tem-se a desagradável sensação de que a legislação existe como simples justificativa da existência dos legisladores, que pouco se importam, no geral, com sua aplicação”.

\section{CONSIDERAÇÕES FINAIS}

Embora haja um aparto jurídico sólido relativo à conservação ambiental, sobretudo de forma expressiva, vetando a ação do abatimento das árvores no país, o cenário local leva inferir que muito ainda há de ser feito neste sentido. A simples previsão legislativa, proibindo o abatimento das árvores, não resolve os problemas fundamentais dos residentes. Conforme visto, a não observância do referido preceito normativo, deve-se, em parte, o problema de não efetivação de grande parte do direito fundamental, tais como: a saúde, a educação, a habitação.

É importante que haja medidas eficazes em diferentes níveis. Está-se, pois, diante de dois grandes valores principiológicos, o primeiro, atrelado dignidade do ser humano (direito à habitação, à saúde, à educação), e o segundo, atrelado ao meio ambiente ecologicamente equilibrado (princípio do direito ambiental). Infere-se, os seguintes: se existe a probabilidade de judicializar indivíduo pela suposta infração ambiental, igualmente é o dever do cidadão judicializar o Estado pelo não cumprimento das suas funções. Não obstante, independentemente da máquina judiciária, é fundamental haver a sensibilidade, a conscientização, de toda sociedade sobre a importância da estabilidade ecológica no 
| Desmatamento, bem-estar comunitário e desenvolvimento sustentável: uma análise integrada em São Tomé e Príncipe - África|

| Manuel D'Assunção do Nascimento José da Costa | Lúcio Correia Miranda|

arquipélago santomense. Lembre-se que a cooperação comunitária é extremamente importante ao processo do desenvolvimento sustentável local.

Assim, é imprescindível a promoção de análise integrada do sistema socioambiental, investigando uma estratégia que estabeleça conservação ambiental e, simultaneamente, promova o bem-estar comunitário. Portanto, é necessário promover a análise, incorporando as necessidades fundamentais dos residentes e os cuidados que os mesmos devem ter no relacionamento com a natureza, no processo da subtração de recurso natural para satisfação das suas necessidades e sua ânsia de poder. Para tanto, urge apresentação das possíveis diretrizes que possam reger uma atuação de forma sustentável, propondo a importância de um plano de manejo alternativo e sustentável dos recursos naturais, bem como os mecanismos de atratividade para o seu uso.

Oportuno destacar sobre a necessidade de política pública voltada à educação ambiental. A sociedade precisa ser educada frente ao desafio da sustentabilidade ecológica. A educação ambiental deve ser promovida desde ensino básico, destacando que é fundamental cooperação dos pais e de toda sociedade para formação de caráter dos filhos, tudo com vista à melhoria na conservação do meio ambiente no arquipélago santomense.

\section{REFERÊNCIAS}

BRASIL. Resolução Conama $\mathbf{n}^{\circ}$ 001, de 23 de janeiro de 1986. Publicado (D.O.U) e entrado em vigor na mesma data, 17/2/1986. Disponível em: $<$ http://www.mma.gov.br/port/conama/res/res86/res0186.html>. Acesso em: 08 set. 2016.

CASTRO, Iná Elias de. Geografia e política: território, escalas de ação e instituições. Rio de Janeiro: Bertrand Brasil, 2005.

CAVALCANTI, Roberto et al. Meio Ambiente, Geografia, Ecologia: Desflorestamento. Sua Pesquisa, Terra das Artes, 2004. Disponível em: $<$ http://www.suapesquisa.com/o que e/desflorestamento.htm>. Acesso em: 26 ago. 2015.

CENTRO DE CIÊNCIA DO SISTEMA TERRESTRE. Instituto Nacional de Pesquisas Espaciais - INPE. Há cinco ilhas do Pacífico que já desapareceram. São Paulo: INPE, 2015. Disponível em: <http://www.ccst.inpe.br/ha-cinco-ilhas-do-pacifico-que-jadesapareceram/>. Acesso em: 14 set. 2016.

ePORTUGUÊSe OMS. Parques do Mundo: Parque Natural Ôbo (São Tomé e Príncipe). 2013. Disponível em: < http://eportuguese.blogspot.com.br/2013/05/parques-do-mundoparque-natural-obo-sao.html >. Acesso em: 15 ago. 2016. 
| Desmatamento, bem-estar comunitário e desenvolvimento sustentável: uma análise integrada em São Tomé e Príncipe - África|

| Manuel D'Assunção do Nascimento José da Costa | Lúcio Correia Miranda |

FERNANDES, Albertino et al. São Tomé e Príncipe: as causas e as consequências da produção de carvão. TERRAGAIA: Comunicação Ambiente Sustentabilidade, São Tomé, série especial, 01 out. $2014 . \quad$ Disponível em: <https://terragaia.wordpress.com/2014/10/01/producao-de-carvao-em-sao-tome-eprincipe-causas-e-consequencias/>. Acesso em: 15 ago. 2016.

FILHO, José Sarney. Agenda 21. Brasília: MMA/PNUD, 2000.

FREITA, Raquel Coelho de. A Igualdade Liberal. Revista da Faculdade de Direito, Fortaleza, v. 34, n. 1, p. 409-448, 2013.

GARCIA, Ricardo; ROCHA, Daniel. 130 anos de natureza numa semana. [entre 2010 e 2016]. Disponível em: <https://www.publico.pt/temas/jornal/130-anos-de-naturezanuma-semana-26940376>. Acesso em: 17 ago. 2016.

INSTITUTO NACIONAL DE ESTATÍSTICA DE SÃO TOMÉ E PRÍNCIPE. IV recenseamento geral da população e habitação. São Tomé, 2012. Disponível em: < http://www.ine.st/Documentacao/Recenseamentos/2012/TemasRGPH2012/1 DINA MICA $\% 20$ DA $\% 20$ POPULACAO $\% 20$ Recenseamento $\% 202012$.pdf $>$. Acesso em: 03 set. 2016.

LOPES, Mário. São Tomé \& Príncipe: desflorestação ameaça biodiversidade. Global Voices, 2012. Disponível em: <https://pt.globalvoices.org/2012/10/10/sao-tomeprincipe-biodiversidade-oleo-palma/>. Acesso em: 17 ago. 2016.

MIRANDA, Lúcio Correia. Diagnóstico geoecológico como subsídio ao planejamento ambiental na ilha do Príncipe - São Tomé e Príncipe - África. 2013. 193f. Dissertação (Mestrado em Desenvolvimento e Meio Ambiente) - Programa de Pósgraduação em Desenvolvimento e Meio Ambiente, Universidade Federal do Ceará, Fortaleza, 2013.

MORAES, Antônio Carlos Robert. Geografia Pequena História Crítica. 14. ed. São Paulo: Hucitec, 1995.

PEQUENO, Ovídio. ODM: São Tomé e Príncipe e o desafio da sustentabilidade. Eco D, Biodiversidade, Rádio ONU, Nova York, 27 dez. 2010. Disponível em: $<$ http://www.ecodesenvolvimento.org/conexao-onu/odm-sao-tome-e-principe-investe-

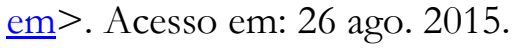

PIERRET, Agnes. Diga NÃo ao Óleo de Palma! Ian Somerhalder Foundation, 2013. Disponível em: <http://www.isfoundation.com/pt-br/news/diga-n\%C3\%A3o-ao\%C3\%B3leo-de-palma $>$. Acesso em: 10 set. 2016.

PINSKY, Jaime. Cidadania e Educação. São Paulo: Contexto, 1998.

RELVAS, João. Aumenta atividade no vulcão da ilha cabo-verdiana do Fogo. Observador, Lusa, Cabo Verde, 02 jan. 2015. Disponível em: $<\underline{\text { http://observador.pt/2015/01/02/aumenta-atividade-no-vulcao-da-ilha-cabo-verdiana- }}$ fogo/>. Acesso em: 26 ago. 2015. 
| Desmatamento, bem-estar comunitário e desenvolvimento sustentável: uma análise integrada em São Tomé e Príncipe - África|

| Manuel D'Assunção do Nascimento José da Costa | Lúcio Correia Miranda|

RODRIGUES, José Manuel Mateo; SILVA, Edson Vicente da. Educação Ambiental e Desenvolvimento Sustentável: problemática, tendências e desafios. Fortaleza: Edições UFC, 2009.

DEUTSCHE WELLE. São Tomé e Príncipe aposta em casas amigas do ambiente. DW. Made for minds: programas, São Tomé e Príncipe, 2012. Disponível em: $<$ www.dw.com/pt/são-tomé-e-príncipe-aposta-em-casas-amigas-do-ambiente/a16294861>. Acesso em: 15 ago. 2016.

SÃO TOMÉ E PRÍNCIPE. Constituição da república Democrática de São Tomé e Príncipe: Assembleia Nacional. São Tomé. Promulgada em 2003. Disponível em: < http://www2.camara.leg.br/saotomeeprincipe/constituicao/constituicao-da-republicademocratica-de-s.tome-e\#a10>. Acesso em: 17 ago. 2016.

SÃO TOMÉ E PRÍNCIPE. Lei n. ${ }^{\circ}$ 05/2001, Lei de florestas. Assembleia Nacional. São Tomé. Promulgado em 2001. Disponível em: < http://faolex.fao.org/docs/pdf/sao72017.pdf>. Acesso em: 17 ago. 2016.

SEIFFERT, Mari Elizabete Bernardini. Gestão Ambiental: instrumentos, esferas de ação e educação ambiental. São Paulo: Atlas, 2010.

SOUZA, F. M. N. et al. Análise de riscos como instrumento para sistemas de gestão ambiental. Revista Ibero-Americana de Ciências Ambientais, Aquidabã, v. 3, n. 1, p. 17-41, 2012. Disponível em: $<$ http://sustenere.co/journals/index.php/rica/article/viewFile/ESS2179-6858.2012.001. 0002/144>. Acesso em: 10 out. 2016.

TIBA. Tiba em Lobata, São Tomé e Príncipe. Lobata, [2012]. Disponível em: $<$ http://www.tibarose.com/port/projetos-sao tome principe.php $>$. Acesso em: 05 nov. 2015.

VEIGA, Abel. Empresa belga assinou com o estado são-tomense acordo para transformar o arquipélago num dos principais produtores de óleo vegetal de África a partir de 2014. TÉLA NÓN. São Tomé, 2009. Disponível em: < http://www.telanon.info/economia/2009/10/22/2055/empresa-belga-assinou-com-oestado-sao-tomense-acordo-para-transformar-o-arquipelago-num-dos-principaisprodutores-de-oleo-vegetal-de-africa-a-partir-de-2014/>. Acesso em: 05 nov. 2015.

TELÁ NÓN. Plantar São Tomé e Príncipe. São Tomé, 2012. Disponível em: $<$ http://www.telanon.info/sociedade/2012/03/19/9994/\%E2\%80\%9Cplantar-sao-tomee-principe $\% \mathrm{E} 2 \% 80 \% 9 \mathrm{D} />$. Acesso em: 15 ago. 2016.

ZATTI, Vicente. Autonomia e Educação em Immanuel Kant e Paulo Freire. Porto Alegre: EDIPUCRS, 2007.2 Disponível em: $<$ http://www.pucrs.br/edipucrs/online/autonomiaeeducacao.pdf $>$. Acesso em: 08 out. de 2016.

World Wildlife Fund - WWF. Chegamos ao limites! 8 de agosto dia da sobrecarga da terra. Brasília: WWF, 2016. Disponível em: <http://www.wwf.org.br/natureza brasileira/especiais/pegada ecologica/overshootday/ >. Acesso em: 04 nov. 2015. 